\title{
Influence of Malocclusions In Development of New Relationships
}

\author{
Muhammad Azeem ${ }^{1}$ \\ Muhammad Ansar Bilal ${ }^{2}$ \\ Muhammad Ayaz ${ }^{3}$ \\ Arfan Ul Haq ${ }^{4}$
}

\author{
BDS, FCPS \\ BDS \\ BDS \\ MDS, FCPS, MCPS, BDS
}

OBJECTIVE: For young adults, dental attractiveness is a key factor that influences social relationships. The objective of present study was to find out the influence of malocclusion in development of new relationships.

METHODOLOGY: In this cross sectional study, photographs of 6 willing young adults ( 3 boys, 3 girls) were used. Of these, photographs of 2 adults ( 1 boy, 1 girl) were manipulated (Photoshop, CS3, Adobe System) to produce photographs of different types of orthodontic conditions. A total of 90 evaluator age 20 to 25 years were asked to evaluate these photographs on a questionnaire based on Visual Analog Scale. Data was analyzed using SPSS software (version 21.0). RESULTS: All malocclusions interfered negatively in development of new social relationships among adults, with inadequate incisal show at smile, being the type of malocclusion that led to the highest level of rejection $(\mathrm{P}=0.001)$. CONCLUSION: All malocclusions interfered negatively in development of new social relationships among adults, with some having more influence than others.

KEY WORDS: Malocclusion; Dental esthetics; Occlusion.

HOW TO CITE: Azeem M, Bilal MA, Ayaz M, Ul Haq A. Influence of Malocclusions In Development of New Relationships. J Pak Dent Assoc 2017;26(4):146-50.

DOI: https://doi.org/10.25301/JPDA.264.146

Received: 20 September, 2017, Accepted: 08 November, 2017

\section{INTRODUCTION}

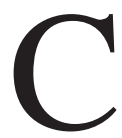
ontemporary diagnostic tripod consists of macroesthetics (the face), miniesthetics (the smile), and microesthetics (tooth and gingival shape and form). ${ }^{1-4}$ In general, the goal of orthodontics is to uplift the patient's life by enhancing dentofacial functioning and aesthetics. ${ }^{5}$ From this perspective, the role of orthodontics is analogous to that of several other medical specialties, such as orthopaedics and plastic surgery, in which the patient's problems often do not result from disease but rather from distortions. Contemporary orthodontics goal is to establish emotional and physical wellness. ${ }^{5}$ Dentofacial distortions create a disability that can influence physical and mental health. Appropriate treatment can be important for the patient's well-being.

As per Dion et al., ${ }^{6}$ "What is beautiful is good." The relationship between physical attractiveness and social relationships is already proven. ${ }^{7-9}$ Adults are especially inclined to start conversations with physically attractive people. ${ }^{10}$ Many factors related to malocclusion have been

1. Assistant Professor Orthodontics, Faisalabad Medical University, Pakistan. 2. House officer, de'Montmorency College of Dentistry, Lahore, Pakistan.

3. House officer, de'Montmorency College of Dentistry, Lahore, Pakistan

4. Dean, Professor \& Head of Orthodontics, Faisalabad Medical University, Pakistan.

Corresponding author: "Dr. Muhammad Azeem”<dental.concepts@ hotmail.com> reported to affect the perceptions of facial esthetics, namely anterior tooth alignment, tooth shape and position, lip thickness, symmetric gingival or tooth contour, lip profile, overjet, and so on. ${ }^{11-17}$

Studies have demonstrated that perceptions of facial esthetics influence psychological development. ${ }^{18-19}$ A teacher's perceptions of a student's attractiveness can influence the teacher's expectations and evaluation of the student. ${ }^{20}$ Young adults with healthy smiles are considered more attractive, perceived as being more intelligent, and regarded as those with the best social skills. ${ }^{21}$ However, past research has not shown a possible influence of malocclusion in young adults on the development of new social relationships. ${ }^{22}$ Therefore, objective of present study was to find out the influence of malocclusion in development of new social relationships among adults.

\section{METHODOLOGY}

This cross-sectional study was conducted at Department of Orthodontics, de'Montmorency College of Dentistry and Faisalabad Medial University, from 1-1-2017 to 15-8-2017. Institutional ethical board approval (2015/3074-B) was obtained. A total of 90 young adult patients acting as evaluators, were randomly selected from orthodontic outdoor 
department and were asked to score the various manipulated full face smiling photographs.

Inclusion criteria of evaluator were: 20 to 25 years of age, irrespective of gender, willing to participate in the study, no history of orthodontic treatment, not student of any medical or dental courses, and having no eye sight issues. Inclusion criteria of participants' whose photographs were used and manipulated: 20 to 25 years of age, irrespective of gender, willing to participate in the study, agreed to the manipulation of their smile, gave consent to publish such manipulated photographs, having normal harmonious smile and no previous history of orthodontic treatment. Extraoral full face smiling photographs of six willing young adults were used and included three pictures of boys and three pictures of girls. The pictures of two subjects ( 1 boy and 1 girl) were manipulated to produce five types of orthodontic conditions: diastema, anterior open bite, crowding, excessive gingival display on smile, inadequate incisal show. The pictures were manipulated using software (Photoshop, CS3, Adobe System) and changes were made at dentition level only to produce malocclusions, so that the face remained unaltered.

This resulted in production of twelve photographs i.e. two normal non-malocclusion photographs ( 1 boy and 1 girl), ten manipulated malocclusion photographs ( 5 of boy and 5 of girl). Five manipulated photographs of one willing boy are shown as an example in Figure I.

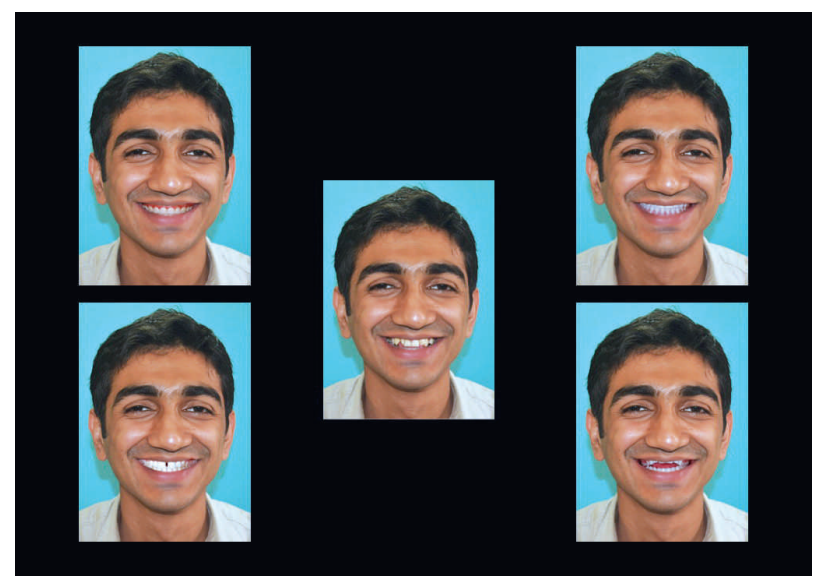

Figure I: Manipulated smile photographs

Photographs were divided into six group's i.e. normal non malocclusion, diastema, anterior open bite, crowding, excessive gingival display on smile, and inadequate incisal show photograph group. Since there were six groups of pictures, initially selected 90 evaluators were asked to score each group of photograph.

Before scoring smile, each photograph was accompanied by 5 questions. Questions were: (1) Person with this type of smile attracts you? (2) Would you like to talk with a person with this type of smile? (3) Would you dinner with a person with this type of smile? (4) Would you start a friendship with a person with this type of smile? (5) Would you like to meet with a person with this type of smile, again? After answering these questions, the evaluators were asked to grade smile using a visual analog scale $0-10,0$ for complete disagreement and 10 for complete agreement. At the time of data analysis, only answers directed to the opposite gender were taken in to account.

Data was analyzed using SPSS software (version 21.0). Since data was not normally distributed, scores per photographs were evaluated by means of the Kruskal-Wallis test. Between the groups comparison was made by MannWhitney test. The level of significance was determined at $\mathrm{p} \leq 0.05$.

\section{RESULTS}

The mean age of the evaluators was $22.2 \pm 1.1$ years, with $55 \%$ being males. (Table I).

\begin{tabular}{|l|l|}
\hline Variables & Evaluators \\
\hline $\begin{array}{l}\text { Age } \\
\text { (Mean } \pm \text { S.D) }\end{array}$ & $22.2 \pm 1.1$ years \\
\hline Boys \% & $55 \%$ \\
\hline Girls \% & $45 \%$ \\
\hline
\end{tabular}

Table I: Age and gender distribution

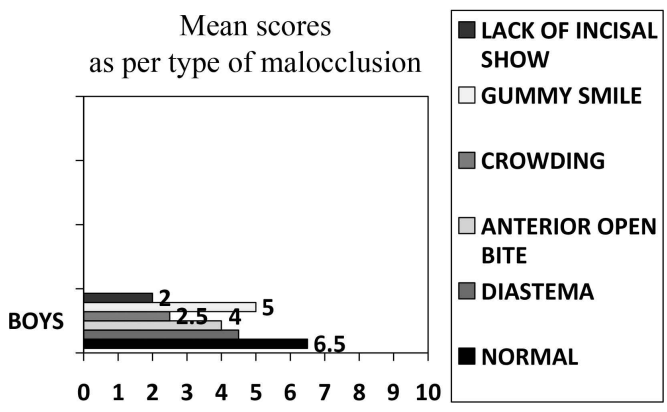

Figure II: Mean scores as per type of malocclusion, in boys.

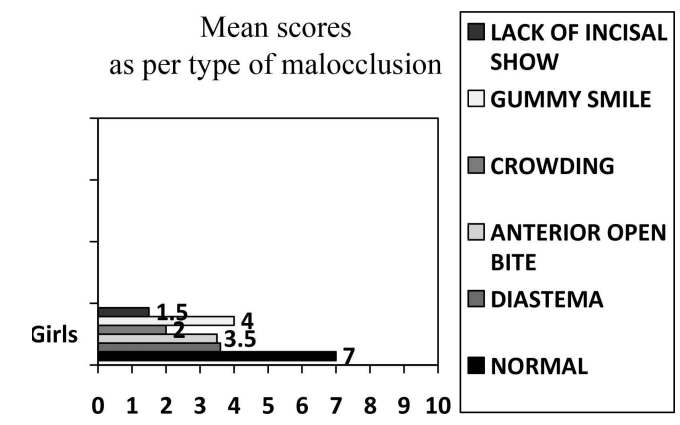

Figure III: Mean scores as per type of malocclusion, in girls. 
In Tables II and III, the answers of boys and girls, respectively, are tabulated with regard to the interest in development of new relationships according to the type of orthodontic conditions. Significant differences were found in the frequencies of replies to all questions asked. $(p=0.001)$

For both males and females, all smile type had a negative influence in development of new relationships among adults, when compared with the harmonious smile. (Figure II \& III)

Inadequate incisal show was the malocclusion that most negatively interfered in the development of new relationships. (Figure II \& III)

Gummy smile was the malocclusion that least negatively interfered in the development of new relationships. (Figure II \& III)

For boys, inadequate incisal show followed by crowding, was found out to be the orthodontic conditions that most negatively interfered in the development of new relationships. Similarly for girls, inadequate incisal show followed by crowding, was found out to be the orthodontic conditions

Table II. Development of new relationships (Replies of boys)

\begin{tabular}{|c|c|c|c|c|c|c|c|}
\hline \multirow[b]{2}{*}{ Reply } & \multicolumn{6}{|c|}{ Photographs } & \multirow[b]{2}{*}{ P Value } \\
\hline & Normal & Open bite & Gummy smile & Crowding & $\begin{array}{r}\downarrow \text { Incisal } \\
\text { show }\end{array}$ & Diastema & \\
\hline \multicolumn{8}{|c|}{ Attractive smile? } \\
\hline - Yes, \% & 69.6 & 30.4 & 34.1 & 28.3 & 10.8 & 31.2 & \multirow[t]{2}{*}{$0.001 *$} \\
\hline No, $\%$ & 30.4 & 69.6 & 65.9 & 71.7 & 89.2 & 68.8 & \\
\hline \multicolumn{8}{|l|}{ Talking? } \\
\hline Yes, $\%$ & 68.8 & 44.4 & 50.5 & 23.2 & 20.2 & 39.5 & \multirow[t]{2}{*}{$0.001 *$} \\
\hline No, $\%$ & 31.2 & 55.6 & 49.4 & 76.8 & 79.8 & 60.5 & \\
\hline \multicolumn{8}{|l|}{ Dinner? } \\
\hline Yes, \% & 75.5 & 47.2 & 66.3 & 48.8 & 15.4 & 46.3 & \multirow[t]{2}{*}{$0.001 *$} \\
\hline No, $\%$ & 24.4 & 52.8 & 33.7 & 51.2 & 84.6 & 53.7 & \\
\hline \multicolumn{8}{|c|}{ Friendship? } \\
\hline Yes, \% & 60.4 & 30.3 & 42.2 & 36.4 & 13.7 & 26.4 & \multirow[t]{2}{*}{$0.001 *$} \\
\hline No, $\%$ & 39.6 & 69.7 & 57.8 & 63.6 & 86.3 & 73.6 & \\
\hline \multicolumn{8}{|c|}{ Again meeting? } \\
\hline Yes, \% & 60.2 & 30.7 & 35.4 & 76.2 & 82.9 & 44.2 & \multirow[t]{2}{*}{$0.001 *$} \\
\hline No, $\%$ & 39.8 & 69.3 & 64.6 & 23.8 & 17.1 & 55.8 & \\
\hline
\end{tabular}

*Chi-square test.

Table III. Development of new relationships (Replies of girls)

\begin{tabular}{|c|c|c|c|c|c|c|c|}
\hline \multirow[b]{2}{*}{ Reply } & \multicolumn{6}{|c|}{ Photographs } & \multirow[b]{2}{*}{ P Value } \\
\hline & Normal & Open bite & Gummy smile & Crowding & $\begin{array}{r}\downarrow \text { Incisal } \\
\text { show }\end{array}$ & Diastema & \\
\hline \multicolumn{8}{|c|}{ Attractive smile? } \\
\hline - $\quad$ Yes, \% & 67.3 & 31.2 & 32.5 & 26.2 & 8.7 & 31.1 & \multirow[t]{2}{*}{$0.001 *$} \\
\hline No, \% & 32.7 & 68.8 & 67.5 & 73.8 & 91.3 & 68.9 & \\
\hline \multicolumn{8}{|l|}{ Talking? } \\
\hline Yes, \% & 67.5 & 45.6 & 48.5 & 21.6 & 19.3 & 39.1 & \multirow[t]{2}{*}{$0.001 *$} \\
\hline No, \% & 32.5 & 54.4 & 51.5 & 78.4 & 80.7 & 60.9 & \\
\hline \multicolumn{8}{|l|}{ Dinner? } \\
\hline Yes, \% & 74.7 & 48.5 & 64.6 & 46.5 & 13.5 & 46.1 & \multirow[t]{2}{*}{$0.001 *$} \\
\hline No, \% & 25.3 & 51.5 & 35.4 & 53.5 & 86.5 & 53.9 & \\
\hline \multicolumn{8}{|c|}{ Friendship? } \\
\hline Yes, \% & 59.4 & 31.7 & 40.4 & 34.5 & 11.5 & 26.8 & \multirow[t]{2}{*}{$0.001 *$} \\
\hline No, $\%$ & 40.6 & 68.3 & 59.6 & 65.5 & 88.5 & 73.2 & \\
\hline \multicolumn{8}{|c|}{ Again meeting? } \\
\hline Yes, \% & 59.3 & 31.7 & 33.7 & 74.5 & 80.5 & 44.6 & \multirow[t]{2}{*}{$0.001 *$} \\
\hline No, $\%$ & 40.7 & 68.3 & 66.3 & 25.5 & 19.5 & 55.4 & \\
\hline
\end{tabular}

*Chi-square test. 
that most negatively interfered in the development of new relationships. (Figure II \& III)

\section{DISCUSSION}

In today's world, dental micoesthetics and miniesthetics is highly graded, pointing orthodontists to focus on all aspects of micoesthetics and miniesthetics while treating orthodontic patients. ${ }^{1-3}$ According to Palomares et al.,${ }^{23}$ the eyes are on top followed by smile that draws most attention at a first interaction. Ideal arrangement of teeth is must for attractive smile and this ideal arrangement of the teeth when smiling has an impact on social relations. ${ }^{24-25}$ In 1985 , Shaw concluded that kids with an optimal smile were judged to be more beautiful, desirable as friends, more intelligent, and less likely to behave in an aggressive manner than kids with malocclusions. ${ }^{24}$

This study was designed to to find out the influence of malocclusion in development of new relationships among adults. To conceive this research, the methodology part was adopted from study 'Do dental esthetics have any influence on finding a job?' by Pithon et al, ${ }^{14}$ with certain modifications. Modifications includes: Questions adopted together with photographs, 6 surveys were applied instead of 2 and separate investigation of influence of each malocclusion perceivable in a front smiling view. ${ }^{22}$

With regard to malocclusions, the result was that all smile type had a negative influence, which is in agreement with results of previous studies. ${ }^{26-29}$ For specific types of malocclusions, inadequate incisal show was the malocclusion that most negatively interfered in the development of new relationships; this result may be due to the fact that inadequate incisal show indicates characteristics of aging. ${ }^{30}$ Gummy smile was the malocclusion that least negatively interfered in the development of new relationships; this result may be explained by the fact that the gingival smile gives women a younger looking appearance. ${ }^{31}$

The limitation of this study is small sample size; we suggest conducting another multi-centric study of evaluators with larger group size. Because of subjective nature of VAS scores which affects scoring, further studies are suggested to using objective criteria.

\section{CONCLUSION}

- It is concluded that all malocclusions interfered negatively in development of new relationships among adults, with some having more influence than others.

- Inadequate incisal show was the malocclusion that most negatively interfered in the development of new relationships.

- Gummy smile was the malocclusion that least negatively interfered in the development of new relationships.

\section{CONFLICT OF INTEREST}

None declared

\section{REFERENCES}

1. Sarver DM. Orthodontics \& esthetic dentistry: Mission possible! A Broader Approach to Interdisciplinary Esthetic Treatment. J Cosmetic Dent. 2016;31.

2. Brandão RC, Brandão LB. Finishing procedures in Orthodontics: dental dimensions and proportions (microesthetics). Dental press J Orthodo. 2013;18:147-74. 3. Asad S, Bokhari F, Ahsan W. Proportional mesio-distal dimension of permanent maxillary teeth. Pak Orthod J. 2015;7:30-4.

4. Erdemir, U, Yildiz E, and Yucel T. "Esthetic Parameters/Smile Design." Esthetic and Functional Management of Diastema. Springer International Publishing, 2016. 53-64.

5. Turley PK. Evolution of esthetic considerations in orthodontics. Am J Orthod Dentofac Orthop. 2015;148:3749.

6. Dion K, Berscheid E, Walster E. What is beautiful is good. J Personality Soc Psychol. 1972;24:285.

7. Traebert ES, Peres MA. Do Malocciusions Affect the Individual's Oral Health-Related Quality of Life?. Oral health Prev Dent. 2007;5:3-12

8. Meyer-Marcotty P, Stellzig-Eisenhauer A. Dentofacial self-perception and social perception of adults with unilateral cleft lip and palate. J Orofac Orthop. 2009;70:224-36. 9. Tatarunaite E, Playle R, Hood K, Shaw W, Richmond S. Facial attractiveness: a longitudinal study. American J Orthod Dentofac Orthop. 2005;127:676-82.

10. Garcia S, Stinson L, Ickes W, Bissonnette V, Briggs SR. Shyness and physical attractiveness in mixed-sex dyads. J Personality Soc Psychol. 1991;6:35.

11. Rosa M, Olimpo A, Fastuca R, Caprioglio A. Perceptions of dental professionals and laypeople to altered dental esthetics in cases with congenitally missing maxillary lateral incisors. Progress Orthod. 2013;14:1-7.

12. Mehl C, Wolfart S, Vollrath O, Wenz HJ, Kern M. Perception of dental esthetics in different cultures. Int $\mathrm{J}$ Prosthodont. 2014;27:523-9.

13. Yin L, Jiang M, Chen W, Smales RJ, Wang Q, Tang L. Differences in facial profile and dental esthetic perceptions between young adults and orthodontists. Am J Orthod Dentofac Orthop. 2014;14:750-6.

14. Pithon MM, Nascimento CC, Barbosa GC, da Silva Coqueiro R. Do dental esthetics have any influence on 
finding a job?. Am J Orthod Dentofac Orthop. 2014;146:4239.

15. Kokich VO, Kokich VG, Kiyak HA. Perceptions of dental professionals and laypersons to altered dental esthetics: asymmetric and symmetric situations. Am J Orthod Dentofac Orthop. 2006;130:141-51.

16. Soh J, Chew MT, Chan YH. Perceptions of dental esthetics of Asian orthodontists and laypersons. Am J Orthod Dentofac Orthop. 2006;130:170-6.

17. de Paula, Júnior DF, Santos NC, da Silva ÉT, Nunes MF, Leles CR. Psychosocial Impact of Dental Esthetics on Quality of Life in Adolescents: Association with Malocclusion, SelfImage, and Oral Health-Related Issues. Angle Orthod. 2009; 79:1188-93.

18. Albino JE, Alley TR, Tedesco LA, Tobiasen JA. Esthetic issues in behavioral dentistry. Annals Behav Med. 1990;12:148-55.

19. Cavior N, Lombardi DA. Developmental aspects of judgment of physical attractiveness in children. Dev Psychol. 1973;8:67.

20. Clifford MM, Walster E. The effect of physical attractiveness on teacher expectations. Sociol edu. 1973:24858.

21. Henson ST, Lindauer SJ, Gardner WG, Shroff B, Tufekci

$\mathrm{E}$, Best AM. Influence of dental esthetics on social perceptions of adolescents judged by peers. Am J Orthod Dentofac Orthop. 2011;140:389-95.

22. Pithon MM, dos Santos CR, Lima Santos ND, Aguiar Sales Lima SO, da Silva Coqueiro R, dos Santos RL. Impact of malocclusion on affective/romantic relationships among young adults. Angle Orthodont. 2015;86:638-43. 23. Palomares NB, Celeste RK, de Oliveira BH, Miguel JA.
How does orthodontic treatment affect young adults' oral health-related quality of life?. Am J Orthod Dentofac Orthop. 2012;141:751-8.

24. Shaw WC, Rees G, Dawe M, Charles CR. The influence of dentofacial appearance on the social attractiveness of young adults. Am J Orthodont. 1985;87:21-6. 25. Schols JG. Dental development and facial growth during adolescence. Nederlands tijdschrift voor tandheelkunde. 2013;120:605-9.

26. Claudino D, Traebert J. Malocclusion, dental aesthetic self-perception and quality of life in a 18 to 21 year-old population: a cross section study. BMC Oral Health. 2013;13:3.

27. Aikins EA. Self-perception of malocclusion among Nigerian adolescents using the aesthetic component of the IOTN. Open Dent J. 2012;6:61.

28. Meyer-Marcotty P, Kochel J, Boehm H, Linz C, Klammert U, Stellzig-Eisenhauer A. Face perception in patients with unilateral cleft lip and palate and patients with severe Class III malocclusion compared to controls. J CranioMaxillofac Surg. 2011;39:158-63.

29. Abu Alhaija ES, Al-Nimri KS, Al-Khateeb SN. Selfperception of malocclusion among north Jordanian school children. Europ J Orthodont. 2005;27:292-5. 30. Saroja K, Surendra HS. A study of postgraduate students' endogamous preference in mate selection. Ind J Behav. 1991;15:1-13.

31. Pithon MM, Santos AM, Campos MS, Couto FS, dos Santos AF, Coqueiro RD, Oliveira DD, Tanaka OM. Perception of laypersons and dental professionals and students as regards the aesthetic impact of gingival plastic surgery. Eur J Orthod. 2014;36:173-8. 